\title{
The central coherence account of autism revisited: Evidence from the ComFor study
}

\author{
Ilse L.J. Noens *, Ina A. van Berckelaer-Onnes \\ University of Leiden, The Netherlands
}

Received 6 April 2007; received in revised form 17 May 2007; accepted 31 May 2007

\begin{abstract}
According to the central coherence account, people with autism have a tendency to focus on local rather than global processing. However, there is considerable controversy about the locus of the weak drive for central coherence. Some studies support enhanced bottom-up processing, whereas others claim reduced top-down feedback. The results of the standardization study of the ComFor - a clinical instrument for the indication of augmentative communication, based on the central coherence account - were reviewed within the perspective of this debate. One hundred fifty-five individuals with intellectual disability and the autistic disorder were individually matched with 155 individuals with intellectual disability without the autistic disorder according to their level of daily living skills. The finding that individuals with the autistic disorder exhibit a higher discrepancy between the presentation and representation scores of the ComFor is consistent with expectations on the basis of the central coherence theory, but does not stipulate whether this is due to enhanced bottom-up or reduced top-down processing. Item level analyses, however, show that enhanced local processing emerges most clearly on those items whereby the establishment of meaning (global processing) is not supportive, suggesting that enhanced bottom-up processing and reduced global feedback are interconnected.
\end{abstract}

(C) 2007 Elsevier Ltd. All rights reserved.

Keywords: Central coherence; Perception; Local; Global; Autism; Intellectual disability

\section{Introduction}

The central coherence account, first conceptualized by Frith (1989), is one of the most prominent cognitive-psychological theories on Autism Spectrum Disorders (ASD). Central

\footnotetext{
* Corresponding author at: University of Leiden, Clinical Child and Adolescent Studies, P.O. Box 9555, 2300 RB Leiden, The Netherlands. Tel.: +317152740 83; fax: +31715273619.

E-mail address: noens@fsw.leidenuniv.nl (I.L.J. Noens).
} 
coherence refers to the normal tendency to process incoming information globally and in context, thus aiding human beings to make sense and see structure and meaning. This tendency operates at the expense of attention to details (Frith, 1989, 2003). People with ASD, however, exhibit a 'Weak drive for Central Coherence' (WCC), a tendency to focus on local rather than global information. This processing-bias should not be considered a deficit but instead a specific cognitive style, since (1) a weaker drive for central coherence predicts skills as well as weaknesses (Happé, 1999, 2000); (2) the drive for central coherence seems to vary from strong to weak in the normal population (Briskman, Happé, \& Frith, 2001; Happé, Briskman, \& Frith, 2001); (3) people with ASD tend to strive more for coherence when instructed to do so (Jolliffe \& Baron-Cohen, 1999; Plaisted, Swettenham, \& Rees, 1999). During the last decade, the WCC account acquired an established position in the cognitive-psychological debate on ASD (for reviews, see Happé, 1999, 2000; Happé \& Frith, 2006; Hill \& Frith, 2003; Noens \& van Berckelaer-Onnes, 2005). As yet, WCC is non-specific as to the underlying processes, at both the cognitive and neural levels (Happé \& Frith, 2006; Hill \& Frith, 2003). On the one hand, there seems to be enhanced bottom-up processing, on the other, reduced top-down feedback.

An important variant of the central coherence account, the theory of 'Enhanced Perceptual Processing' (EPP), postulates that ASD is not characterized by poor integration of information in a Gestalt but by enhanced discrimination of the individual elements (Mottron \& Burack, 2001; Mottron, Burack, Iarocci, Belleville, \& Enns, 2003; Mottron, Peretz, \& Ménard, 2000; O'Riordan, 2000; Plaisted, 2001; Plaisted, O’Riordan, \& Baron-Cohen, 1998a, 1998b; Plaisted, Saksida, Alcántara, \& Weisblatt, 2003; Plaisted et al., 1999). The EPP account claims that local processing is indeed enhanced (bottom-up), but not at the expense of global processing (topdown).

The debate between WCC and EPP is on-going; both accounts present data favoring their theses. As yet, evidence has been obtained predominantly by experimental studies among high-functioning individuals with ASD. To our knowledge, there are only two studies of central coherence skills in low-functioning individuals (Happé, 1996; van Lang, Bouma, Sytema, Kraijer, \& Minderaa, 2006), in which children and adolescents with moderate intellectual disability ${ }^{1}$ with and without the autistic disorder were compared (Happé, 1996). The ComFor study comprised even lowerfunctioning individuals. Although the study was not explicitly intended to settle the debate on WCC and EPP, it yields data that might shed a different light on the debate.

\section{The ComFor}

The ComFor (Forerunners in Communication; in Dutch: Voorlopers in CommunicatieVerpoorten, Noens, \& van Berckelaer-Onnes, 2004; English version in press (Verpoorten et al., in press); for details: see Noens, van Berckelaer-Onnes, Verpoorten, \& van Duijn, 2006) is a clinical instrument to obtain a precise indication of individualized communicative interventions, in particular augmentative communication, for people with ASD with limited or no verbal communication. Section 3 of this paper contains more information on the objective, the target group, the structure, and the psychometric properties of the ComFor. For a proper understanding of the relevance of the present study for the debate between WCC and EPP, it is important to mention that the ComFor was developed within the framework of WCC and intended to be a translation of the notion of WCC into an educational approach.

\footnotetext{
1 'Intellectual disability' refers to the ICD-10/DSM-IV-TR term 'mental retardation'.
} 
Following Verpoorten (1996), one can distinguish four levels of sense-making: sensation, presentation, representation and metarepresentation. At the level of sensation, sensory experiences are pivotal; there is neither functional nor referential meaning. At the level of presentation, one perceives information within a concrete context. The individual now understands functional meanings. The level of representation is reached when reference or symbolic skills exist. Representation implies awareness that the symbol and the referent are not identical but two clearly separate entities (Bates, 1979). At the level of metarepresentation, the information behind the primary information is perceived. It concerns meanings detached from the first representation. The four levels of sense-making are ordered developmentally. However, the levels should not be conceptualized as clearly distinct entities but rather as interconnecting stages (Noens et al., 2006). The extent to which an individual is able to make sense of experiences is dependent on his or her abilities, the specific situation, the broader context, etcetera. For a little baby, coffee running through a coffee machine will merely yield an olfactory and/or auditory sensation; for an adult, that same sensory experience can evoke the representation of drinking coffee and - when expecting a coffee break - a feeling of relaxation.

The ComFor only measures perception and sense-making of non-transient forms of communication at the levels of presentation and representation. At the level of presentation, identical objects or pictures have to be sorted according to shape, color, matter, and/or size. Sense-making beyond these literally perceptible features is not needed to arrive at the right solution. The tasks can thus be resolved on the basis of local information processing. At the level of representation, non-identical objects or pictures have to be sorted on the basis of sense-making beyond the concrete, literally perceptible features, thus more global information processing but it only concerns primary and functional meanings.

Since presentation precedes representation developmentally, all participants will generally obtain higher scores on presentation than on representation. According to the WCC account (local rather than global processing) however, people with ASD are expected to display a higher discrepancy between scores at the presentation level and scores at the representation level than people without ASD. According to the EPP account (enhanced local processing), people with ASD are expected to have enhanced scores for the presentation tasks without reduced scores for the representation tasks in comparison to people without ASD.

\section{Method}

\subsection{Participants}

All 310 participants of the current study participated in a larger study on the psychometric properties of the ComFor (Noens et al., 2006). The sample consists of children and adults from a Dutch-speaking region (Netherlands and Flanders) with a developmental level between 12 and 60 months on the domain of daily living skills, measured with the Dutch version of the Vineland Screener (Sparrow, Carter, \& Cicchetti, Unpublished data). The total sample comprises two subsamples: (1) a group of children and adults with intellectual disability (ID) and the autistic disorder (AD) $(n=155)$; (2) a group of children and adults with ID without $\mathrm{AD}(n=155)$. The characteristics of the subsamples are given in Table 1.

Only participants with the autistic disorder (DSM-IV-TR, 299.00) were included in the AD subsample. Participants with related disorders such as Pervasive Developmental Disorder Not Otherwise Specified (PDD-NOS) and/or additional sensory or motor disabilities were excluded. As an extra check, mainly to prevent inclusion of undiagnosed individuals with $\mathrm{AD}$ within the subgroup 
Table 1

Characteristics of the two paired subsamples

\begin{tabular}{|c|c|c|c|c|c|c|c|}
\hline \multirow[t]{2}{*}{ Subsample } & \multirow[t]{2}{*}{$n$} & \multicolumn{2}{|c|}{ CA (months) } & \multicolumn{2}{|c|}{ DLS (months) } & \multicolumn{2}{|c|}{$\operatorname{Sex}(\%)$} \\
\hline & & $\bar{M}$ & S.D. & $\bar{M}$ & S.D. & Male & Female \\
\hline ID with $\mathrm{AD}$ & 155 & 204.22 & 157.13 & 41.32 & 11.90 & 79.4 & 20.6 \\
\hline ID without $\mathrm{AD}$ & 155 & 221.88 & 185.64 & 41.34 & 11.89 & 58.7 & 41.3 \\
\hline Total & 310 & 213.08 & 171.97 & 41.33 & 11.88 & 69.0 & 31.0 \\
\hline
\end{tabular}

Note: CA, chronological age; DLS, developmental level for daily living skills.

ID without AD, the AUTI-R (van Berckelaer-Onnes \& Hoekman, 1991) - a Dutch screening instrument - was administered to all participants. Only individuals with the AUTI-R classification 'autistic disorder' (thus not: 'no classification' and 'no autistic disorder') were included in the subgroup ID with AD, and only individuals ith the AUTI-R classification 'no autistic disorder' (not: 'autistic disorder' or 'no classification') were included in the subgroup ID without AD.

In accordance with Fombonne (1992), Lord et al. (1997), and Kraijer (2000), who suggested to use the level of daily living skills as matching variable to compare people with ID with and without $\mathrm{AD}$, each child with $\mathrm{AD}$ was individually matched with a child without $\mathrm{AD}$ with the same level of daily living skills (Vineland Screener age equivalents: maximum difference 15 days), and each adult with AD was matched with an adult without AD with the same level of daily living skills (Vineland Screener age equivalents: maximum difference 15 days).

\subsection{Measures}

\subsubsection{ComFor}

As mentioned before, the ComFor is a clinical instrument for the indication of individualized augmentative communication. The ComFor answers two questions: first; what is the most suitable form for augmentation; second, at which level of sense-making can the means chosen be offered? As far as the first question is concerned, the ComFor comprises objects, pictograms, photographs, line drawings, and written text. With respect to the second question, the ComFor includes the levels of presentation and representation. The level of sensation is not directly assessed, but communication should be realized at the level of sensation if an individual does not meet the conditions for presentation. The level of metarepresentation is left out of consideration. The interpretation of the ComFor is content-referenced, not norm-referenced.

People with ASD with limited or no verbal communication form the primary target group of the ComFor. Hence, it is for young children with ASD or children and adults with ASD and ID. The scope of the ComFor varies from a (psychomotor) developmental level of about 12 months to about 60 months.

The ComFor consists of two levels with a total of five series and 36 items. The presentation level consists of three series; the representation level comprises two series. Appendix A shows the structure of the ComFor; in Appendix B the items of the ComFor are described briefly. The script of the test activity is very straightforward: each item is organized as a sorting task. Series 1 is the so-called 'learning series', in which sorting is trained by means of assembling tasks (fitting objects into a hole in closed boxes). The supporting design gradually fades, requiring a more complex object-object association. In series 2 identical objects have to be sorted according to shape, color, matter, and/or size. Series 3 involves sorting identical photographs, line drawings, pictograms, and written text. All of the items of series 3 have to be sorted according to shape. The 
only exception is item 8 (color photographs of comb, spoon, and toothbrush), which can also be sorted according to color. Consequently, all items in series 2 and 3 can be resolved on the basis of local information processing. Sense-making beyond the literally perceptible features (a more global orientation) is not necessary, although for some items it can offer support to find the right solution. If, for example, identical copies of photographs of a woman writing, reading and drinking have to be sorted (item 14), then grasping the meaning of the photographs can ease adequate sorting. Similarly, item 15 is easier to sort if one is able to understand the line drawings of combing hair, eating and brushing teeth, although it is not required to solve the item correctly. However, a more global orientation is not supportive for all the items of series 2 and 3. The letters E, F, and L (item 13), for example, are meaningless as long as one is illiterate, which applies to the majority of the participants of this study. While local information processing was sufficient for sorting the items of the presentation level, a more global orientation was generally needed to be able to sort the items of the representation level. If, for example, different balls, dolls, and cars (item 18) have to be sorted, then focusing on local features (i.e. color or shape) would be contra-productive, since it could lead to wrongly associating a green car with a green ball (color) or the head of a puppet with a ball (shape). In series 4, one has to sort within one form, whereas series 5 involves sorting different forms. In terms of difficulty, the items ascend within each series (ordination following normal development), but the series overlap: the start of each series is easier than the end of the preceding one (with the exception of the transition from series 1 to series 2).

Preliminary data (Noens et al., 2006) confirm the reliability and validity of the ComFor. Internal consistency, inter-rater and test-retest reliability were found to be good (all coefficients for item and series scores 0.80 or higher; all coefficients for level and total scores 0.90 or higher, except 0.84 test-retest reliability for representation score). Construct validity (internal structure, convergent and divergent patterns) was established in many ways. The criterion-related validity has yet to be ascertained, since predictive data are not available at the moment.

\subsubsection{Vineland Screener 0-6 years}

The level of functioning of the participants was determined with the Vineland Screener, a quick, reliable and valid measurement of personal and social sufficiency, which was specifically developed for research purposes (Sparrow et al., Unpublished data). The Vineland Screener 0-6 years (a combination of the American versions $0-2 ; 11$ and 3-5; 11) was recently adapted and standardized on a Dutch sample (Scholte, van Duijn, Dijkxhoorn, Noens, \& van Berckelaer-Onnes, in press). An important difference between the original American Vineland Screener and the Dutch adaptation is that the former is administered as a short interview, whereas the latter is standardized as a questionnaire. The Dutch normative data were also used for the Flemish participants.

The reliability and validity of the American version of the Vineland Adaptive Behavior Scales have been studied and described extensively. With respect to the Dutch Vineland Screener 0-6 years, all coefficients for inter-rater reliability, test-retest reliability, and internal consistency were 0.89 or higher for the total score and each of the domain scores (Scholte et al., in press). The Vineland Screener 0-6 years distinguishes four domains of adaptive functioning: communication, daily living skills, socialization, and motor skills. As mentioned before, the level of functioning for the domain of daily living skills was used to establish two comparable groups of people with ID with and without AD.

\subsubsection{AUTI-R}

The AUTI-R (van Berckelaer-Onnes \& Hoekman, 1991) is a Dutch screening instrument, aimed at identification of the autistic disorder (AD). Administration of the AUTI-R leads to three 
possible classifications: 'AD', 'no classification' (dubiety), and 'no AD'. The AUTI-R was chosen because of the clear correspondence of the AUTI-R definition with the DSM-IV-TR criteria of AD (Kraijer \& Plas, 2002). All coefficients for inter-rater reliability, test-retest reliability, and internal consistency were 0.90 or higher; cross-validation showed correct classification in $92 \%$ of the cases (van Berckelaer-Onnes \& Hoekman, 1991). It is important to note that the AUTI-R was not standardized for adults and children with severe ID; however, there was no alternative Dutch screening instrument specifically aimed at AD available.

\subsection{Procedure}

Participants were recruited through institutions and special schools for people with ID in the Netherlands and Flanders. The primary caregivers of the participants (parents or professionals) were asked to fill in the Vineland Screener 0-6 years and the AUTI-R. Subsequently, the ComFor was administered by research assistants from the University of Leiden. Their training consisted of a ComFor course, dealing with test procedure and administration pitfalls. Afterwards, they had to carry out a test administration, which was recorded and discussed afterwards. The whole process of data collection was supervised by one of the researchers (IN). The administrations were video recorded to enable repeat scoring for reliability purposes.

\subsection{Data analysis}

All data were entered into SPSS 11.0. A subtraction score (presentation level score minus representation level score) was introduced as a simple method to make the discrepancy between the two levels visible. The differences between the two clinical groups (ID with and without AD) were evaluated by conducting $t$-tests for independent samples on the series, levels, subtraction and total scores. Subsequently, $\chi^{2}$-tests were performed for each of the items to gain more detailed insight into the origin of the differences between people with and without AD. A conservative significance level of 0.01 was adopted throughout all analyses to compensate for multiple testing; Bonferroni corrections were also implemented to explore whether the results are not just chance findings. The $t$-tests are significant after Bonferroni correction when $p<0.01$ $(0.05 / 4=0.0125)$, the $\chi^{2}$-tests when $p<0.001(0.05 / 36=0.0014)$.

\section{Results}

Table 2 shows the results of the $t$-tests for independent samples for the ComFor-scores. The variance was high in both groups. The only difference which reaches significance concerns the

Table 2

Comparison between the two paired subsamples

\begin{tabular}{|c|c|c|c|c|c|}
\hline \multirow[t]{2}{*}{ ComFor } & \multicolumn{2}{|c|}{$\begin{array}{l}\text { ID with AD } \\
(n=155)\end{array}$} & \multicolumn{2}{|c|}{$\begin{array}{l}\text { ID without AD } \\
(n=155)\end{array}$} & \multirow[t]{2}{*}{$t($ d.f. $=308)$} \\
\hline & $M$ & S.D. & $M$ & S.D. & \\
\hline Presentation & 14.79 & 7.12 & 13.24 & 6.08 & 2.06 \\
\hline Representation & 4.77 & 4.84 & 4.34 & 4.12 & 0.85 \\
\hline Subtraction & 10.01 & 4.00 & 8.90 & 3.09 & $2.75^{*}$ \\
\hline Total & 19.56 & 11.50 & 17.58 & 9.92 & 1.62 \\
\hline
\end{tabular}

\footnotetext{
$p<0.01$
} 
Table 3

Items which significantly differentiate between the paired subsamples

\begin{tabular}{|c|c|c|}
\hline Series & Item & $\chi^{2}($ d.f $=1)$ \\
\hline Series 2 & $\begin{array}{l}5 \\
6 \\
7\end{array}$ & $\begin{array}{l}8.07^{*} \\
8.75^{*} \\
9.60^{*}\end{array}$ \\
\hline Series 3 & $\begin{array}{l}13 \\
16 \\
17\end{array}$ & $\begin{array}{l}16.34^{\text {** }} \\
14.70^{\text {** }} \\
14.20^{\text {** }}\end{array}$ \\
\hline Series 4 & 19 & $9.52^{*}$ \\
\hline
\end{tabular}

${ }^{*} p<0.01$.

** $p<0.001$.

fact that the results of the group with $\mathrm{AD}$ exhibit a higher discrepancy than the results of the group without AD (see 'subtraction' in Table 2; $p=0.006$, significant after Bonferroni correction). People with $\mathrm{AD}$ achieved relatively higher scores at the presentation level than at the representation level, compared to people without $\mathrm{AD}$. With respect to the presentation score, the difference between the two groups just misses significance at $p<0.01$.

To gain more insight into the origin of the difference found in Table $2, \chi^{2}$-tests were performed on the items of the ComFor. Table 3 lists the items revealing significant differences between the two samples. In all cases, the group with AD obtained better results than the group without AD. The items that provided the best discrimination between samples are items 13, 16, and 17 ( $p<0.001$; significant after Bonferroni correction). They involve sorting cards with the letters $\mathrm{E}$, F, and L (item 13); cards with the numbers 25, 26, and 29 (item 16); and cards with the words 'bed', 'bad', and 'kam' (in English: bed, bath, and comb) (item 17), respectively. Intriguingly, for illiterate participants - the majority of the sample - these are the only 'meaningless' items in series 3 . The cards thus have to be sorted according to shape; sense-making beyond the literally perceptible features (more global processing) cannot offer any support. Although sense-making beyond literalness is not necessarily required for sorting the other items of series 3, establishing meaning can offer extra support.

The differences on four other items just miss significance after Bonferroni correction. Series 2 contains three items for which the group with $\mathrm{AD}$ obtained better results $(p<0.01)$ : item 5 (small circles, big circles, ovals), item 6 (cubes, flat blocks, thick blocks), and item 7 (dessert, tea and soup spoons). Remarkably, as in series 3, these are exactly the items requiring good shape discrimination; sense-making beyond literalness does not offer much support. With respect to series 4 , there is a difference between the two subsamples on item 19 (spoons, knives and forks from different cutlery) ( $p<0.01)$. Since this item involves sorting of non-identical information, it is placed at the representation level of the ComFor. However, just like the previously mentioned items from series 2 and 3, it can be resolved by focusing on shape (thus sense-making at the level of presentation).

\section{Discussion}

\subsection{Enhanced bottom-up or reduced top-down processing?}

The finding that the ComFor results for individuals with ID and AD exhibit significantly more discrepancy than the results for individuals with ID without AD $(p=0.006$; significant after 
Bonferroni correction) is consistent with expectations on the basis of the WCC account. People with $\mathrm{AD}$ focus on local rather than global information. This finding is hardly surprising, since the ComFor was developed within the WCC perspective. Though, it still does not answer the question about the locus of WCC effects: enhanced bottom-up or reduced top-down processing?

On the basis of the EPP account, one could predict enhanced scores for presentation tasks without reduced scores for representation tasks. At the presentation level, the group with ID and AD indeed achieved better scores, but the difference between the two groups does not reach significance at $p<0.01$; at the representation level, there was no difference between the results of the two groups. The level scores do not reveal significant differences with respect to the locus of the WCC effect, but the differences in item scores were significant. The group with ID and AD obtained significantly better results for seven items (three items: $p<0.001$, significant after Bonferroni correction; four items: $p<0.01$ ), all of which could be sorted according to shape. The group with ID without AD did not obtain significantly better results for any of the items. At first sight, this could be interpreted as support for the EPP account; enhanced bottom-up processing and, in particular, shape discrimination can explain results for each of the seven items.

However, the findings cannot be explained by enhanced shape discrimination alone, since the group with $\mathrm{AD}$ did not obtain better results for all items requiring good shape discrimination. In series 3 all pictures can be sorted according to shape. It would be comprehensible if the differences between groups were mainly evident for the most difficult items featuring shape discrimination, but this does not apply since the items best discriminating between groups are not all items at the end of the series (items 14 and 15 do not reach significance). A closer look at the items for which the most significant $(p<0.001)$ differences were found reveals that they are the only items in the series for which sense-making beyond literalness cannot offer any support, since letters (item 13), numbers (item 16) and words (item 17) do not bear any meaning for lowfunctioning individuals. For all other items in series 3 (items 8-9-10-11-12-14-15) establishment of meaning can support adequate sorting. Although preliminary and in need of replication, one can hypothesize that superior discrimination (bottom-up) in the event of ID and $\mathrm{AD}$ is most clear in the absence of the benefit of establishing meaning (top-down), which subsequently suggests that enhanced bottom-up processing and reduced top-down feedback are interconnected.

Summarizing, enhanced bottom-up processing indeed seems to exist in ASD but - contrary to the EPP hypothesis - alongside reduced top-down processing. The original formulation of Frith (1989) who defined WCC as a tendency to focus on local rather than global information still seems to be defensible, although the WCC account has moved towards an emphasis on superiority in local processing rather than a deficit in global processing (Happé \& Frith, 2006). The terminology 'weak central coherence' possibly overemphasizes reduced top-down processing to the detriment of enhanced bottom-up processing.

\section{2. 'Local' versus 'global'?}

In Section 2 of this paper, four levels of sense-making were described: sensation, presentation, representation, and metarepresentation (Verpoorten, 1996). When WCC and EPP studies are situated at these levels of sense-making, the definition of 'local' versus 'global' seems to vary, therefore the debate on the differences between WCC and EPP might be dependent upon what is defined as 'local' or 'global'. Experimental tasks establishing enhanced bottom-up processing usually occur at the presentation level, whereas tasks establishing reduced top-down processing usually occur at higher representation or even metarepresentation levels. In EPP experiments, 
sense-making beyond literally perceptible features is not necessary to resolve the task. For the example of the Navon hierarchical letters task (e.g. small $X$ s forming a larger $K$; Plaisted et al., 1999), it is possible to distinguish a local and a global condition; the task itself, however, is located at the presentation level, whether it is the local or the global condition.

Another interesting example is the Embedded Figures Test (EFT), a task that requires the ability to suppress the global picture in order to find a hidden shape; as first demonstrated by Shah and Frith (1983) and later replicated by Jolliffe and Baron-Cohen (1997) and Ropar and Mitchell (2001), people with AD are significantly better in the EFT. The disembedding task itself is to be carried out at the presentation level, but sense-making beyond literalness is contra-productive: task-irrelevant meanings at the representation level can be distracting, thus complicating the process of disembedding at the presentation level. Since individuals with AD are 'hindered' less by sense-making at the representation level, better results are indeed to be expected. Again, as in the ComFor study, enhanced bottom-up processing is demonstrated most clearly when sensemaking at the representation level is not supportive. The difference between the ComFor and the EFT is that establishment of meaning is simply not supportive in the former case and is contraproductive in the latter case.

A robust example of reduced top-down processing, replicated in many studies, concerns the fact that individuals with $\mathrm{AD}$ fail to use sentence context spontaneously to disambiguate the pronunciation of homographs (Frith \& Snowling, 1983; Happé, 1997; Jolliffe \& Baron-Cohen, 1999; Snowling \& Frith, 1986). When comparing this task with the EFT, it is clear that the homograph task (as many other linguistic WCC tasks) lies at a higher conceptual (thus representation or even metarepresentation) level. Similar evidence exists for the use of context in visual processing (e.g. Jolliffe \& Baron-Cohen, 2001).

Summarizing, enhanced bottom-up/local processing seems to exist alongside reduced top-down/global processing. In experimental studies, the level of sense-making required (the stimulus complexity) might determine whether enhanced bottom-up and/or reduced topdown effects will be found. Enhanced bottom-up processing is probably most evident in tasks at the presentation level where establishing meaning is not supportive (in lower-functioning individuals) or contra-productive (in higher-functioning individuals). To date, it is unclear how 'global' the task should be to elicit the reduced top-down effect. Presumably, this is dependent on the level of functioning of the participants. High-functioning individuals with AD may only have difficulties with tasks at the metarepresentation level, whereas lowfunctioning individuals may already experience difficulties with some representation tasks. The present study shows that the items of the ComFor are not 'global' enough to elicit group differences at the representation level, but one must take into account that the ComFor only demands monomodal, non-transient and spatially organized information processing; people with $\mathrm{AD}$ have more difficulties with multimodal, transient and temporally organized stimuli (e.g. Fay \& Schuler, 1980; Prizant \& Schuler, 1987; Wetherby, Prizant, \& Schuler, 2000).

\subsection{Directions for future research}

Future research is obviously needed to clarify the nature of WCC. To date, the debate on the locus of WCC effects has been obscured by two major problems: (1) the definition of local and global varies across studies; (2) distinguishing between two levels of information processing is probably insufficient to characterize the exact locus of WCC effects. The four levels of sense-making discussed above (sensation, presentation, representation, and 
metarepresentation) might offer an interesting starting-point but also need further refinement. Moreover, since the level of functioning presumably influences sense-making and perception, longitudinal research is indispensable. It will also be necessary to search for specific subgroups within the autism spectrum. Although the current study only included participants with the core $\mathrm{AD}$, the variance within results was high. It is likely that the higher discrepancy between scores at the presentation level and scores at the representation level in people with $\mathrm{AD}$ (compared to people without $\mathrm{AD}$ ) becomes more manifest in specific subsamples.

In the end, each cognitive-psychological theory of ASD must serve two key purposes: on the one hand, it should offer indications for a neurobiological substrate; on the other hand, it should offer insight into the behavioral aspects of ASD and clues for assessment and intervention. With respect to the indications for a neurobiological substrate, the coexistence of reduced top-down alongside enhanced bottom-up processing is in accordance with the suggestion of Happé $(1999,2000)$ and Frith (2003) that the core problem in the case of ASD might be to join the top-down and bottom-up information streams. One possibility is that this bottleneck in information processing is linked to a profusion of synapses (neuronal overgrowth) and reduced pruning and connectivity (Frith, 2004, 2003; Tager-Flusberg \& Joseph, 2003; for functional MRI evidence of underconnectivity in autism, see Just, Cherkassky, Keller, \& Minshew, 2004).

Despite the growing body of publications on WCC, the experimental accomplishments have as yet hardly been translated into clinical practice. The development of the ComFor (Noens et al., 2006) should be considered an attempt to find clues for assessment and intervention on the basis of WCC notions. The current version of the ComFor focuses on the lower levels of sense-making. Alongside improvement of the ComFor, a similar instrument for the higher levels of representation and metarepresentation is in development.

\section{Acknowledgements}

We would like to thank Roger Verpoorten and Gijs van Duijn for their contribution to the development of the ComFor. Furthermore, we are especially grateful to all participants and their caregivers, students and research assistants who participated in the ComFor project. The Effatha Guyot Group and the University of Leiden financed the study. This article was submitted in part fulfillment of the first author's PhD Degree at the University of Leiden. 


\section{Appendix A. Structure of the ComFor}

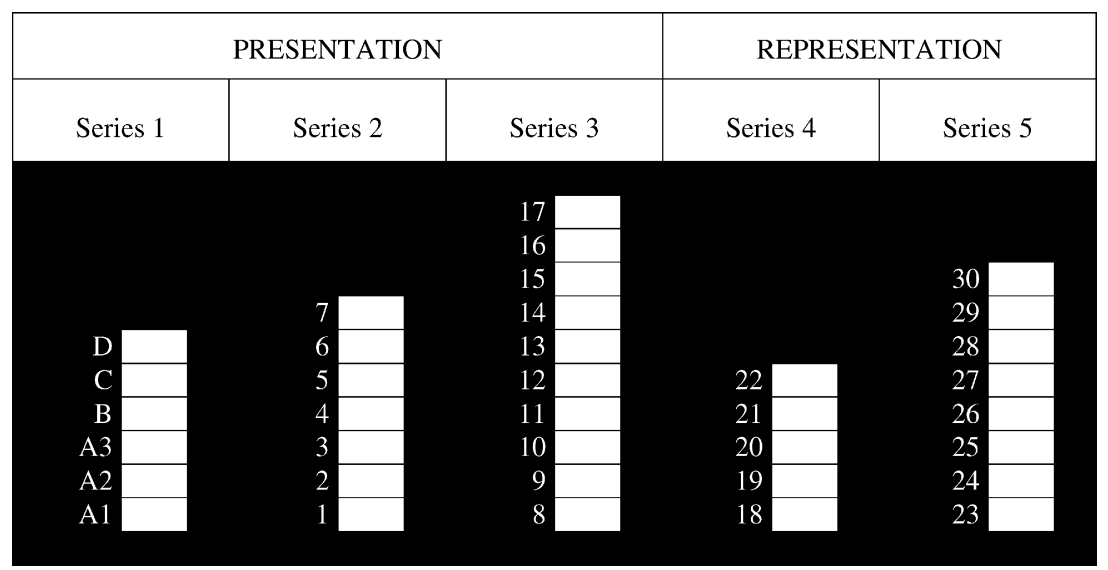

Series 1: $\quad$ Assembling objects (so-called 'learning series')

Series 2: $\quad$ Sorting objects

Series 3: $\quad$ Sorting pictures

Series 4: $\quad$ Sorting within one form

Series 5: $\quad$ Sorting with different forms

\section{Appendix B. Short description of the ComFor items}

\section{Series Item Description}

$1 \quad$ A1 Assembling balls in a closed box

A2 Assembling blocks in a closed box

A3 Assembling rings in a closed box

B Assembling rings and balls in closed boxes

C Assembling blocks, balls and rings in closed boxes

D Assembling blocks and balls in closed boxes, spoons in open box

21 Sorting identical combs, spoons, toothbrushes

Sorting identical chequers, screws, little sticks

Sorting identical spoons, knives, forks

Sorting identical blue, yellow, red checkers

Sorting identical small circles, big circles, ovals

Sorting identical cubes, thin blocks, wide blocks

7 Sorting identical dessert, tea, soup spoons

38 Sorting identical color photographs of comb, spoon, toothbrush

9 Sorting identical line drawings of comb, spoon, toothbrush

10 Sorting identical pictograms of comb, spoon, toothbrush

11 Sorting identical black/white photographs of combing hair, eating, brushing teeth

12 Sorting identical pictograms of reading, writing, drinking

13 Sorting identical letters E, F, L

14 Sorting identical black/white photographs of one person reading, writing, drinking

15 Sorting identical line drawings of combing hair, eating, brushing teeth

16 Sorting identical numbers 25, 26, 29

17 Sorting identical words bed, bad, kam (English: bed, bath, comb) 


\section{Appendix B (Continued)}

$4 \quad 18$ Sorting different balls, dolls, cars

19 Sorting different spoons, knives, forks

20 Sorting functionally related objects: toothbrush-toothpaste, pencil-notebook, fork-plate

21 Sorting photographs of woman, ball, car in different situations

22 Sorting photographs of comb, toothbrush, spoon in different situations

523 Sorting pen, comb, cup with photographs of the same objects

24 Sorting photographs of scissors, bottle, spoon with similar (but somewhat different) objects

25 Sorting scissors, bottle, spoon to pictograms of the objects

26 Sorting pictograms of scissors, bottle, spoon with pictograms of clipping, pouring, eating with a spoon

27 Sorting pen, comb, cup with photographs of writing, combing hair, drinking in a neutral context

28 Sorting photographs of writing, combing hair, drinking in a complex context

29 Sorting the words bed, bad, kam (English: bed, bath, comb) with corresponding photographs

30 Sorting photographs of writing, reading, drinking with corresponding words

\section{References}

Bates, E. (1979). Intentions, conventions, and symbols. In E. Bates, L. Benigni, I. Bretherton, L. Camaioni, \& V. Volterra (Eds.), The emergence of symbols: Cognition and communication in infancy (pp. 33-68). New York: Academic.

Briskman, J., Happé, F., \& Frith, U. (2001). Exploring the cognitive phenotype of autism: Weak "central coherence" in parents and siblings of children with autism: II. Real-life skills and preferences. Journal of Child Psychology and Psychiatry, 42, 309-316.

Fay, W. H., \& Schuler, A. L. (Vol. Eds.). (1980). Emerging language in autistic children. In R. L. Schiefelbusch (Series Ed.). Language intervention series, Vol. 5. Baltimore, MD: University Park Press.

Fombonne, E. (1992). Diagnostic assessment in a sample of autistic and developmentally impaired adolescents. Journal of Autism and Developmental Disorders, 22, 563-581.

Frith, C. (2004). Is autism a disconnection disorder? The Lancet Neurology, 3, 577.

Frith, U. (1989). Autism. Explaining the enigma. Oxford, England: Blackwell.

Frith, U. (2003). Autism. Explaining the enigma (2nd ed.). Oxford, England: Blackwell.

Frith, U., \& Snowling, M. (1983). Reading for meaning and reading for sound in autistic and dyslexic children. Journal of Developmental Psychology, 1, 329-342.

Happé, F. (1996). Studying weak central coherence at low levels: Children with autism do not succumb to visual illusions. Journal of Child Psychology and Psychiatry and Allied Disciplines, 37, 873-877.

Happé, F. (1999). Understanding assets and deficits in autism: Why success is more interesting than failure. The Psychologist, 12, 540-546.

Happé, F. (2000). Parts and wholes, meaning and minds: Central coherence and its relation to theory of mind. In S. BaronCohen, H. Tager-Flusberg, \& D. J. Cohen (Eds.), Understanding other minds. Perspectives from developmental cognitive neuroscience (2nd ed., pp. 203-221). Oxford, NY: Oxford University Press.

Happé, F. G. E. (1997). Central coherence and theory of mind in autism: Reading homographs in context. British Journal of Developmental Psychology, 15, 1-12.

Happé, F., Briskman, J., \& Frith, U. (2001). Exploring the cognitive phenotype of autism: Weak "central coherence" in parents and siblings of children with autism: I. Experimental tests. Journal of Child Psychology and Psychiatry, 42, 299-307.

Happé, F., \& Frith, U. (2006). The weak coherence account: Detail-focused cognitive style in autism spectrum disorders. Journal of Autism and Developmental Disorders, 1, 5-25.

Hill, E. L., \& Frith, U. (2003). Understanding autism: Insights from mind and brain. Philosophical Transactions of The Royal Society of London, Series B, 358, 281-289.

Jolliffe, T., \& Baron-Cohen, S. (1997). Are people with autism and Asperger syndrome faster than normal on the embedded figures test? Journal of Child Psychology and Psychiatry, 38, 527-534.

Jolliffe, T., \& Baron-Cohen, S. (1999). Linguistic processing in high-functioning adults with autism or Asperger syndrome: Is local coherence impaired? Cognition, 71, 149-185.

Jolliffe, T., \& Baron-Cohen, S. (2001). A test of central coherence theory: Can adults with high-functioning autism or Asperger syndrome integrate objects in context? Visual Cognition, 8, 67-101. 
Just, M. A., Cherkassky, V. L., Keller, T. A., \& Minshew, N. J. (2004). Cortical activation and synchronization during sentence comprehension in high-functioning autism: Evidence of underconnectivity. Brain, 127, 18111821.

Kraijer, D. (2000). Review of adaptive behavior studies in mentally retarded persons with autism/pervasive developmental disorder. Journal of Autism and Developmental Disorders, 30, 39-47.

Kraijer, D., \& Plas, J. (2002). Handboek psychodiagnostiek en verstandelijke beperking [Handbook assessment and mental retardation]. Lisse, Netherlands: Swets \& Zeitlinger.

Lord, C., Pickles, A., McLennan, J., Rutter, M., Bregman, J., Folstein, S., et al. (1997). Diagnosing autism: Analyses of data from the Autism Diagnostic Interview. Journal of Autism and Developmental Disorders, 27, 501-517.

Mottron, L., \& Burack, J. A. (2001). Enhanced perceptual functioning in the development of autism. In J. A. Burack, T. Charman, N. Yirmiya, \& P. R. Zelazo (Eds.), The development of autism. Perspectives from theory and research (pp. 131-148). Mahwah, NJ: Erlbaum.

Mottron, L., Burack, J. A., Iarocci, G., Belleville, S., \& Enns, J. T. (2003). Locally oriented perception with intact global processing among adolescents with high-functioning autism: Evidence from multiple paradigms. Journal of Child Psychology and Psychiatry, 44, 904-913.

Mottron, L., Peretz, I., \& Ménard, E. (2000). Local and global processing of music in high-functioning persons with autism: Beyond central coherence? Journal of Child Psychology and Psychiatry, 41, 1057-1065.

Noens, I., \& van Berckelaer-Onnes, I. A. (2005). Captured by details: Sense-making, language and communication in autism. Journal of Communication Disorders, 38, 123-141.

Noens, I., van Berckelaer-Onnes, I. A., Verpoorten, R., \& van Duijn, G. (2006). The ComFor: An instrument for the indication of augmentative communication in people with autism and learning disability. Journal of Intellectual Disability Research, 50, 621-632.

O'Riordan, M. (2000). Superior modulation of activation levels of stimulus representations does not underlie superior discrimination in autism. Cognition, 77, 81-96.

Plaisted, K. (2001). Reduced generalization in autism: An alternative to weak central coherence. In J. A. Burack, T. Charman, N. Yirmiya, \& P. R. Zelazo (Eds.), The development of autism: Perspectives from theory and research (pp. 149-169). Mahwah, NJ: Erlbaum.

Plaisted, K., O’Riordan, M., \& Baron-Cohen, S. (1998a). Enhanced discrimination of novel, highly similar stimuli by adults with autism during a perceptual learning task. Journal of Child Psychology and Psychiatry, 39, 765775 .

Plaisted, K., O’Riordan, M., \& Baron-Cohen, S. (1998b). Enhanced visual search for a conjunctive target in autism: A research note. Journal of Child Psychology and Psychiatry, 39, 777-783.

Plaisted, K., Saksida, L., Alcántara, J., \& Weisblatt, E. (2003). Towards an understanding of the mechanisms of weak central coherence effects: Experiments in visual configural learning and auditory perception. Philosophical Transactions of The Royal Society of London, Series B, 358, 375-386.

Plaisted, K., Swettenham, J., \& Rees, L. (1999). Children with autism show local precedence in a divided attention task and global attention in a selective attention task. Journal of Child Psychology and Psychiatry, 5, 733-742.

Prizant, B. M., \& Schuler, A. L. (1987). Facilitating communication: Theoretical foundations. In D. Cohen \& A. Donnellan (Eds.), Handbook of autism and pervasive developmental disorders (pp. 316-332). New York: Wiley.

Ropar, D., \& Mitchell, P. (2001). Susceptibility to illusions and performance on visuospatial tasks in individuals with autism. Journal of Child Psychology and Psychiatry, 42, 539-549.

Scholte, E., van Duijn, G., Dijkxhoorn, Y., Noens, I., \& van Berckelaer-Onnes, I. (in press). Vineland Screener 0-6 jaar. Handleiding [Vineland Screener 0-6 years. Manual]. Leiden, Netherlands: PITS.

Shah, A., \& Frith, U. (1983). An islet of ability in autistic children: A research note. Journal of Child Psychology and Psychiatry, 24, 613-620.

Snowling, M., \& Frith, U. (1986). Comprehension in 'hyperlexic' readers. Journal of Experimental Child Psychology, 42, 392-415.

Sparrow, S. S., Carter, A. S., \& Cicchetti, D. Vineland Screener. Overview, reliability, validity, administration and scoring. Unpublished manuscript. New Haven, CT: Yale University.

Tager-Flusberg, H., \& Joseph, R. M. (2003). Identifying neurocognitive phenotypes in autism. Philosophical Transactions of The Royal Society of London, Series B, 358, 303-314.

van Berckelaer-Onnes, I. A., \& Hoekman, J. (1991). Auti-R schaal [Auti-R scale]. Lisse, Netherlands: Harcourt Test Publishers.

van Lang, N. D. J., Bouma, A., Sytema, S., Kraijer, D. W., \& Minderaa, R. B. (2006). A comparison of central coherence skills between adolescents with an intellectual disability with and without comorbid autism spectrum disorder. Research in Developmental Disabilities, 27, 217-226. 
Verpoorten, R. A. W. (1996). Communicatie met verstandelijk gehandicapte autisten: Een multidimensioneel communicatiemodel [Communication with mentally retarded people with autism: A multidimensional communication model]. Nederlands Tijdschrift voor Zorg aan Verstandelijk Gehandicapten, 22, 106-120.

Verpoorten, R., Noens, I., \& van Berckelaer-Onnes, I. A. (2004). The ComVoor-Voorlopers in Communicatie, Handleiding [The ComFor-Forerunners in Communication. Manual]. Leiden, Netherlands: PITS.

Verpoorten, R., Noens, I., \& van Berckelaer-Onnes, I. A. (in press). The ComFor-Forerunners in Communication. Manual. Leiden, Netherlands: PITS.

Wetherby, A. M., Prizant, B. M., \& Schuler, A. L. (2000). Understanding the nature of communication and language impairments. In S. F. Warren, \& M. E. Fey (Series Eds.), A. M. Wetherby, \& B. M. Prizant (Vol. Eds.). Communication and language intervention series, Vol. 9. Autism spectrum disorders. A transactional perspective (pp. 109-141). Baltimore, MD: Brookes. 